\title{
Article \\ Satisfaction Factors with a Dental Unit Chair System in South Korea: A Dentist's Perspective
}

\author{
Keunbada Son ${ }^{1(\mathbb{D},}$, Young-Tak Son ${ }^{1,2}{ }^{(\mathbb{C}}$, Myoung-Uk Jin ${ }^{3, *}$ and Kyu-Bok Lee ${ }^{1,4, *(1)}$ \\ 1 Advanced Dental Device Development Institute, Kyungpook National University, Daegu 41940, Korea; \\ sonkeunbada@gmail.com (K.S.); dudxkr741@naver.com (Y.-T.S.) \\ 2 Department of Dental Science, Graduate School, Kyungpook National University, Daegu 41940, Korea \\ 3 Department of Conservative Dentistry, School of Dentistry, Kyungpook National University, \\ Daegu 41940, Korea \\ 4 Department of Prosthodontics, School of Dentistry, Kyungpook National University, Daegu 41940, Korea \\ * Correspondence: musljin@knu.ac.kr (M.-U.J.); kblee@knu.ac.kr (K.-B.L.); Tel.: +82-053-600-7674 (K.-B.L.)
}

check for updates

Citation: Son, K.; Son, Y.-T.; Jin, M.-U.; Lee, K.-B. Satisfaction Factors with a Dental Unit Chair System in South Korea: A Dentist's Perspective. Healthcare 2022, 10, 437. https:// doi.org/10.3390/healthcare10030437

Academic Editors: Saturnino

Marco Lupi and Takahiro Kanno

Received: 7 December 2021

Accepted: 23 February 2022

Published: 25 February 2022

Publisher's Note: MDPI stays neutral with regard to jurisdictional claims in published maps and institutional affiliations.

Copyright: (C) 2022 by the authors. Licensee MDPI, Basel, Switzerland. This article is an open access article distributed under the terms and conditions of the Creative Commons Attribution (CC BY) license (https:// creativecommons.org/licenses/by/ $4.0 /)$.

\begin{abstract}
This study aimed to survey users' satisfaction with a dental unit chair in order to highlight the elements affecting the dentist's satisfaction. The questionnaire items were drawn up with seven components that constitute a dental unit chair, including the light, patient seat, foot controller, water fountain and cuspidor, monitor, bracket table and controller, and dentist chair. With these questionnaire elements, a pilot experiment was conducted to test the reliability, and reliability analysis was conducted. The scale reliability was checked using Cronbach's alpha coefficient. Bartlett's test of sphericity, the Kaiser-Meyer-Olkin (KMO) measure, and factor analysis were performed to test whether the items would constitute appropriate questionnaire items for the survey. The survey was conducted with 26 dentists with more than three years of clinical experience. A correlation analysis was conducted using Pearson's correlation coefficient (PCC) $(\alpha=0.05)$ to analyze the impact of the factors on the overall satisfaction with the dental unit chair. The items that were strongly correlated with the overall satisfaction score of the dental unit chair were the design and appearance quality of the dental unit chair (PCC $=0.781)$, its maintenance (PCC $=0.784)$, and the overall satisfaction with the water fountain and cuspidor $(\mathrm{PCC}=0.703)(p<0.05)$. Most of the questionnaire items could affect the overall satisfaction with the dental unit chair. Additionally, because the design and appearance quality, maintenance, and overall satisfaction with the water fountain and cuspidor may have the greatest impact on the overall satisfaction with the dental unit chair, the improvement of these elements may bring about the enhancement of the overall satisfaction.
\end{abstract}

Keywords: dental unit chair; satisfaction factor; design; dentist; survey

\section{Introduction}

In dental clinics, the use of a dental unit chair is essential for the diagnosis and treatment of patients [1-3]. Dentists spend most of their office hours in the dental unit chair space for patient care $[4,5]$. In addition to dentists, patients and dental hygienists also use the dental unit chair [6]. The dental unit chair consists of the following components: the light, patient seat, foot controller, water fountain and cuspidor, monitor, bracket table and controller, and dentist chair (Figure 1).

Regarding the light of the dental unit chair, precise light irradiation should be possible to the patient's mouth for medical treatment, and convenience of movement is required for the operator [7]. Furthermore, the color temperature control should be convenient, considering tooth color detection and eye fatigue in various clinical environments [8]. Additionally, considering the influence of illumination, illumination suitable for medical treatment is required for resin polymerization and the prevention of eye fatigue [9]. 


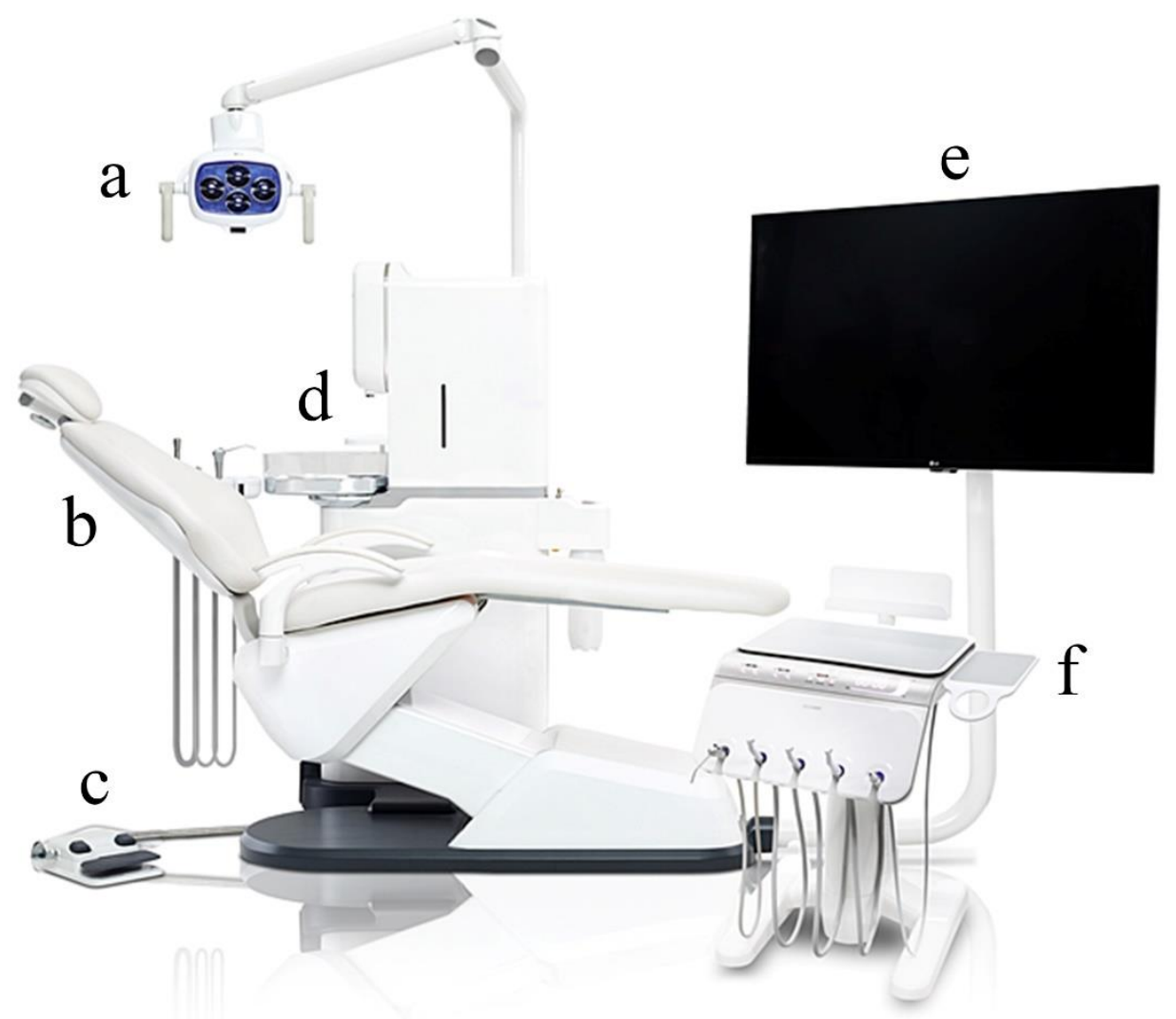

Figure 1. Dental unit chair system. (a) Light, (b) patient seat, (c) foot controller, (d) water fountain and cuspidor, (e) monitor, and (f) bracket table and controller.

The patient seat of the dental unit chair requires a seat that has an appropriate size for the human body of each country, taking into consideration the body shape of the patient and dentist [10]. Furthermore, the optimal back reclining angle and headrest reclining angle are needed for the patient's comfort and the dentist's treatment posture, and appropriate speed is also required, considering the stability and ease of operation when lying or returning the patient to the original position [10]. Additionally, the thickness of the seat is important, considering the shape of the spine and the height of the knee for the dentist's correct treatment posture [11]. The auxiliary handle of the patient seat should not disturb the patient's movement, and instead should but help in this regard. All of these factors may have a significant impact on long-term patient care $[12,13]$.

The foot controller should allow the dentist's intuitive operation and precise use of the handpiece [14]. Additionally, pedal pressures placing less strain on the ankle are required for long-time use [15].

The water fountain and cuspidor should be convenient when they are operated by the patient and assistant [16]. The height and area of the spit sink should be of a size that can minimize inconvenience in movement. Contaminants should be cleaned automatically, and the ease of cleaning management is needed [17]. Additionally, the cup position, the adequacy of the quantity of the water supply, and the water supply speed are important. Furthermore, water purification and wastewater treatment facilities are essential for a pleasant environment and the prevention of cross infection [18-20].

The monitor should be visually comfortable, should provide a great deal of information, and should be of a size which is harmonized with the overall treatment system [21]. An appropriate monitor distance between the dentist and the patient is needed, considering a visually comfortable and moving line. Additionally, the monitor should move stably and smoothly, and should be supported and fixed stably even after the movement without 
any motion. A legible resolution is needed in the treatment process for the display of radiographs, oral photographs, and texts [22].

The bracket table and controller should be of a suitable size for various appliances to be placed on them without affecting the treatment environment [23]. The bracket table and controller should be of a stable weight, should not have any problems with movement, and should allow the stable and convenient mounting and moving of various appliances, as well as providing stability at fixation. Additionally, in the process of controlling several medical devices, a user interface (UI) for the user experience of dentists and assistants is required [24].

The dentist's chair may affect the dentist's musculoskeletal health [25-28]. The backrest angle and shape should be suited for the dentists' health and comfort, and the design should not burden the human body, especially with the dentist's long-term use [29-31]. Additionally, smooth chair movement is required in the process of treatment, considering durability and noise.

A dental unit chair is a necessity in dental clinics, but due to the continuous development of the dental medical device market, various dental unit chairs are being developed, making it difficult for dentists to properly select a dental unit chair when purchasing the dental unit chair. The dental unit chair causes eye fatigue due to light $[8,9]$; should feature an appropriate size and angle of the patient seat [10-13], and the appropriate usability of the foot controller [14,15]; the water fountain and cuspidor should be convenient $[16,17]$; and there should be harmony between the monitor and the overall treatment system [21,22], as well as size and stability of bracket table and controller [23,24]. It is selected by various factors, including the overall design [29-31]. However, it is difficult for dentists to choose a suitable dental unit chair, considering all factors. There are still insufficient studies providing quantitative information regarding the factors to consider while purchasing the dental unit chair. Thus, this study aimed to conduct a survey of user satisfaction with a dental unit chair, and to highlight the elements affecting dentists' satisfaction. The null hypothesis was that the questionnaire items in this study have no correlation with the overall satisfaction with the dental unit chair.

\section{Materials and Methods}

\subsection{Elements of the Survey of Dental Unit Chair User Satisfaction}

Based on clinical experts' advice, important questionnaire items were set up regarding the dental unit chair parts (Table 1). The questionnaire consisted of five items on overall satisfaction (the variety of prices and features, design and appearance quality, maintenance, and overall satisfaction) and the items of each element constituting the dental unit chair (light, patient seat, foot controller, water fountain and cuspidor, monitor, bracket table and controller, and dentist chair) (Table 1). The questionnaire items of each component of the dental unit chair were as follows: 4 items on the light, including the convenience of the light head movement, the convenience of the color temperature control, the influence of illuminance, and overall satisfaction; 7 items on the patient seat, including the appropriate length and area for each part, back reclining angle, headrest recline angle, backrest reclining speed, backrest seat thickness, convenience of the auxiliary handle, and overall satisfaction; 3 items on the foot controller, including the ease of operation, pedal pressure during operation, and overall satisfaction; 7 items on the water fountain and cuspidor, including the ease of operation, height and area of the cuspidor, cup position, water purification and wastewater treatment facilities, water quantity and speed, convenience of cleaning the cuspidor, and overall satisfaction; 6 items on the monitor, including the screen size, distance between monitor and the operator/patient, convenience to move, resolution, arm support, and overall satisfaction; 6 items on the bracket table and controller, including the size, weight, mounting stability, controller UI, stability of the table arm operation, and overall satisfaction; and 4 items on the dentist chair, including the backrest angle and shape, convenience to move, human engineering design, and overall satisfaction) (Table 1). The score of each questionnaire item was evaluated on a Likert scale from 1 to 5 (1: very low satisfaction; 2: low satisfaction; 3 : neither high nor low; 4: high satisfaction; 5: very high satisfaction). 
Table 1. User satisfaction questionnaire items.

Components of the

Dental Unit Chair

Environmental Factors

Clinical Needs

Convenience of light head movement

Convenience of movement for accurate light irradiation into the patient's oral cavity and operator's comfort

Light

Convenience of color temperature control

Influence of illuminance

Color temperature control in consideration of tooth color discrimination and eye fatigue in various clinical environments

Illuminance suitable for treatment considering eye fatigue and resin light curing

Appropriate length and area for each A seat that has a size suitable for the human body in Korea part considering the patient and dentist's body shape

\begin{tabular}{cc} 
part & considering the patient and dentist's body shape \\
\hline Back reclining angle & $\begin{array}{c}\text { Optimal backrest reclining angle for patient comfort and } \\
\text { dentist posture }\end{array}$ \\
\hline Headrest recline angle & $\begin{array}{c}\text { Optimal headrest reclining angle for patient comfort and } \\
\text { dentist posture }\end{array}$
\end{tabular}

Appropriate speed considering both stability and

Patient seat

Backrest reclining speed

Backrest seat thickness

Convenience of auxiliary handle

Foot controller

Water fountain and cuspidor convenience of operation when laying down or returning the patient to the original position
Seat thickness considering the shape of the spine and knee

height for the dentist's correct treatment posture and patient comfort

Convenience that can help without interfering with the patient's movement

Dentist's intuitive operation convenience

Precise use of the handpiece and less pressure on the ankle

Convenience of operation by patients and medical assistants

Height and area to minimize discomfort during movement

The position of the cup considering the convenience of the patient

Pleasant environment and facilities to prevent cross infection
Ease of operation

Ease of operation

Pedal pressure during operation

Ease of operation

The height and area of the cuspidor

Cup position

Water purification and wastewater treatment facilities

Water quantity and speed

Convenience of cleaning the cuspidor Adequacy of water supply quantity and water supply speed

Automatic cleaning of contaminants and ease of cleaning management

Screen size

Visual convenience, various information provision, and monitor size in harmony with the overall medical system

Distance between monitor and Monitor distance considering visual convenience and operator/patient movement for dentists and patients

Monitor Convenience to move Stable and smooth movement

Resolution

Readability of radiographs, oral photographs, and text

Arm support

Even after the monitor is moved, it is fixed by supporting the monitor stably without movement

It is a size that can mount various instruments and does not affect the medical environment

Weight that is stable and does not burden when moving

Bracket table and controller

\begin{tabular}{cc}
\hline Weight & Weight that is stable and does not burden when moving \\
\hline Mounting stability & Stable and convenient mounting of various instruments \\
\hline Controller user interface & $\begin{array}{c}\text { User interface suitable for the user environment of dentists } \\
\text { and medical assistants }\end{array}$ \\
\hline
\end{tabular}

Stability of table arm operation Stability when moving and fixing the table 
Table 1. Cont.

\begin{tabular}{ccc}
\hline $\begin{array}{c}\text { Components of the } \\
\text { Dental Unit Chair }\end{array}$ & Environmental Factors & Clinical Needs \\
\hline & Backrest angle and shape & Backrest angle and shape for dentists' health and comfort \\
\cline { 2 - 3 } Dentist chair & Convenience to move & Soft chair movement considering durability and noise \\
\cline { 2 - 3 } & Human engineering design & $\begin{array}{c}\text { Design that harmonizes with the human body and does not } \\
\text { burden the dentist, especially with long-term use }\end{array}$ \\
\hline
\end{tabular}

A pilot experiment was conducted with an additional 5 participants for a reliability test of the questionnaire elements. Regarding the reliability analysis of the scale, the reliability was checked through Cronbach's alpha coefficient, using statistical software (SPSS release 25.0, IBM, Chicago, IL, USA) $(\alpha=0.05)$. Previous literature reported that a Cronbach's alpha of $>0.9$ indicates reliability and consistency among the items [32-34]. Bartlett's test of sphericity and the Kaiser-Meyer-Olkin (KMO) measure were calculated, indicating the appropriateness of the variable selection for the $\mathrm{KMO}$ value factor analysis (>0.9: excellent, 0.8-0.89: good, 0.7-0.79: suitable, 0.6-0.69: ordinary, 0.5-0.59: unsuitable for use, $<0.5$ : impossible for use in a survey) [35].

Factor analysis was conducted to reduce the variables, remove unnecessary variables, identify variable characteristics, and validate the analysis of the measurement items. Furthermore, communality was calculated, and its value shows how well each variable is described by the extracted factors (the communality value is suitable if they are $>0.5$ ) [36].

The results of the reliability analysis of the survey elements showed that there were excellent reliability and consistency among them (Cronbach's alpha $=0.975)$. The results of the KMO measure and Bartlett's test of sphericity revealed that there was excellent appropriateness of the variable selection for the factor analysis $(\mathrm{KMO}=0.894 ; p<0.001)$. The result of the communality calculation $(>0.5)$ showed how well each variable was described by the extracted factors (Table 2). In the questionnaire, factors in seven of the categories showed the explanatory power of $87.217 \%$ of the global dispersion, excellent reliability, and consistency among the items (Table 2). Thus, we tested whether the factors of this questionnaire constituted appropriate questionnaire items for the survey of the satisfaction with the dental unit chair.

Table 2. Results of the factor analysis and reliability analysis for the extracted questionnaire items.

\begin{tabular}{|c|c|c|c|c|c|c|}
\hline \multirow[b]{2}{*}{ Number } & & \multirow[b]{2}{*}{ Items } & \multicolumn{3}{|c|}{ Factor Analysis } & \multirow{2}{*}{$\begin{array}{l}\text { Cronbach's } \\
\text { Alpha }\end{array}$} \\
\hline & & & Factor Load & Communality & $\begin{array}{c}\text { Contribution } \\
\text { Rate (\%) }\end{array}$ & \\
\hline 1 & \multirow{5}{*}{$\begin{array}{c}\text { Overall } \\
\text { evaluation }\end{array}$} & Price & 0.782 & 0.797 & \multirow{5}{*}{51.504} & \multirow{5}{*}{0.881} \\
\hline 2 & & Versatility of function & 0.557 & 0.929 & & \\
\hline 3 & & $\begin{array}{l}\text { Design and appearance } \\
\text { quality }\end{array}$ & 0.561 & 0.926 & & \\
\hline 4 & & Maintenance & 0.682 & 0.815 & & \\
\hline 5 & & Overall satisfaction & 0.63 & 0.9 & & \\
\hline 6 & \multirow{4}{*}{ Light } & $\begin{array}{l}\text { Convenience of light head } \\
\text { movement }\end{array}$ & 0.819 & 0.878 & \multirow{4}{*}{9.055} & \multirow{4}{*}{0.859} \\
\hline 7 & & $\begin{array}{l}\text { Convenience of color } \\
\text { temperature control }\end{array}$ & 0.851 & 0.757 & & \\
\hline 8 & & Influence of illuminance & 0.829 & 0.959 & & \\
\hline 9 & & Overall satisfaction of light & 0.688 & 0.948 & & \\
\hline
\end{tabular}


Table 2. Cont.

\begin{tabular}{|c|c|c|c|c|c|c|}
\hline \multirow[b]{2}{*}{ Number } & & \multirow[b]{2}{*}{ Items } & \multicolumn{3}{|c|}{ Factor Analysis } & \multirow{2}{*}{$\begin{array}{l}\text { Cronbach's } \\
\text { Alpha }\end{array}$} \\
\hline & & & Factor Load & Communality & $\begin{array}{l}\text { Contribution } \\
\text { Rate (\%) }\end{array}$ & \\
\hline 10 & \multirow{7}{*}{ Patient seat } & $\begin{array}{l}\text { Appropriate length and } \\
\text { area for each part }\end{array}$ & 0.634 & 0.841 & \multirow{7}{*}{6.848} & \multirow{7}{*}{0.898} \\
\hline 11 & & Back reclining angle & 0.84 & 0.832 & & \\
\hline 12 & & Head rest recline angle & 0.572 & 0.744 & & \\
\hline 13 & & Backrest reclining speed & 0.726 & 0.746 & & \\
\hline 14 & & Backrest seat thickness & 0.578 & 0.91 & & \\
\hline 15 & & $\begin{array}{l}\text { Convenience of auxiliary } \\
\text { handle }\end{array}$ & 0.727 & 0.921 & & \\
\hline 16 & & $\begin{array}{l}\text { Overall satisfaction of } \\
\text { patient seat }\end{array}$ & 0.512 & 0.853 & & \\
\hline 17 & \multirow{3}{*}{ Foot controller } & Ease of operation & 0.506 & 0.936 & \multirow{3}{*}{6.191} & \multirow{3}{*}{0.886} \\
\hline 18 & & $\begin{array}{l}\text { Pedal pressure during } \\
\text { operation }\end{array}$ & 0.784 & 0.891 & & \\
\hline 19 & & $\begin{array}{l}\text { Overall satisfaction of foot } \\
\text { controller }\end{array}$ & 0.758 & 0.896 & & \\
\hline 20 & \multirow{7}{*}{$\begin{array}{l}\text { Water fountain } \\
\text { and cuspidor }\end{array}$} & Ease of operation & 0.688 & 0.934 & \multirow{7}{*}{4.596} & \multirow{7}{*}{0.938} \\
\hline 21 & & $\begin{array}{c}\text { The height and area of the } \\
\text { cuspidor }\end{array}$ & 0.608 & 0.937 & & \\
\hline 22 & & Cup position & 0.596 & 0.939 & & \\
\hline 23 & & $\begin{array}{l}\text { Water purification and } \\
\text { wastewater treatment } \\
\text { facilities }\end{array}$ & 0.794 & 0.866 & & \\
\hline 24 & & Water quantity and speed & 0.65 & 0.853 & & \\
\hline 25 & & $\begin{array}{l}\text { Convenience of cleaning } \\
\text { the cuspidor }\end{array}$ & 0.828 & 0.942 & & \\
\hline 26 & & $\begin{array}{l}\text { Overall satisfaction of } \\
\text { water fountain and } \\
\text { cuspidor }\end{array}$ & 0.759 & 0.915 & & \\
\hline 27 & \multirow{6}{*}{ Monitor } & Screen size & 0.845 & 0.943 & \multirow{6}{*}{3.43} & \multirow{6}{*}{0.963} \\
\hline 28 & & $\begin{array}{l}\text { Distance between monitor } \\
\text { and operator/patient }\end{array}$ & 0.886 & 0.892 & & \\
\hline 29 & & Convenience to move & 0.807 & 0.89 & & \\
\hline 30 & & Resolution & 0.57 & 0.807 & & \\
\hline 31 & & Arm support & 0.851 & 0.808 & & \\
\hline 32 & & $\begin{array}{l}\text { Overall satisfaction of } \\
\text { monitor }\end{array}$ & 0.64 & 0.836 & & \\
\hline
\end{tabular}


Table 2. Cont.

\begin{tabular}{|c|c|c|c|c|c|c|}
\hline \multirow[b]{2}{*}{ Number } & & \multirow[b]{2}{*}{ Items } & \multicolumn{3}{|c|}{ Factor Analysis } & \multirow{2}{*}{$\begin{array}{c}\text { Cronbach's } \\
\text { Alpha }\end{array}$} \\
\hline & & & Factor Load & Communality & $\begin{array}{l}\text { Contribution } \\
\text { Rate (\%) }\end{array}$ & \\
\hline 33 & \multirow{6}{*}{$\begin{array}{c}\text { Bracket table and } \\
\text { controller }\end{array}$} & Size & 0.839 & 0.814 & \multirow{6}{*}{3.29} & \multirow{6}{*}{0.974} \\
\hline 34 & & Weight & 0.872 & 0.848 & & \\
\hline 35 & & Mounting stability & 0.819 & 0.877 & & \\
\hline 36 & & Controller user interface & 0.624 & 0.918 & & \\
\hline 37 & & $\begin{array}{c}\text { Stability of table arm } \\
\text { operation }\end{array}$ & 0.559 & 0.905 & & \\
\hline 38 & & $\begin{array}{l}\text { Overall satisfaction of } \\
\text { bracket table and } \\
\text { controller }\end{array}$ & 0.862 & 0.779 & & \\
\hline 39 & \multirow{4}{*}{ Dentist chair } & Back rest angle and shape & 0.789 & 0.801 & \multirow{4}{*}{2.303} & \multirow{4}{*}{0.93} \\
\hline 40 & & Convenience to move & 0.88 & 0.874 & & \\
\hline 41 & & $\begin{array}{l}\text { Human engineering } \\
\text { design }\end{array}$ & 0.518 & 0.939 & & \\
\hline 42 & & $\begin{array}{l}\text { Overall satisfaction of } \\
\text { dentist chair }\end{array}$ & 0.717 & 0.836 & & \\
\hline
\end{tabular}

\subsection{Survey of Dental Unit Chair User Satisfaction}

This survey was conducted with the approval of the Clinical Trial Ethics Committee of Kyungpook National University Dental Hospital (IRB No. KNUDH-2021-04-04-00). The survey was conducted with 26 dentists after the sufficient description of the satisfaction survey with the dental unit chair. Prior to this study, a pilot experiment was conducted with the same materials and methods as this study but with 5 subjects; based on the results, the a priori sample size calculation was performed, using power analysis software ( $\mathrm{G}^{*}$ Power v3.1.9.2; Heinrich-Heine-Universität Düsseldorf, Düsseldorf, Germany) ( $N=26$; correlation $\rho \mathrm{H} 1=0.66$; actual power $=97.36 \%$; power $=97 \% ; \alpha=0.05)$. As for the subject selection, two investigators (K.S. and K.-B.L.) counseled the participants, and those who had active opinions and high interests in the dental unit chair were selected as the subjects. Twenty-six participants were enrolled in the study according to the inclusion and exclusion criteria (Table 3). The participants evaluated the dental unit chair systems used in dental clinics, and the manufacturers of the chair unit systems were as follows: Shinhung (Seoul, Korea), Osstem Implant (Seoul, Korea), Sky Dental (Cheongju, Korea), and Dentium (Seoul, Korea). The survey took about $30 \mathrm{~min}$ per person. The information on the 26 participants is as follows-sex: 16 men and 10 women; mean age: $37.3 \pm 7.7$ years; and mean clinical experience: $9.7 \pm 6.3$ years.

Table 3. Study inclusion and exclusion criteria.

\begin{tabular}{|c|c|}
\hline Inclusion Criteria & Exclusion Criteria \\
\hline $\begin{array}{l}\text { - } \quad \text { Clinical experience }>3 \text { years. } \\
\text { Participants who have sufficient } \\
\text { experience in using the dental unit chair } \\
\text { system. } \\
\text { Participants who fully understand the } \\
\text { purpose of this clinical study and can } \\
\text { participate actively. }\end{array}$ & $\begin{array}{l}\text { Participants who are inappropriate to } \\
\text { participate in clinical trials in the } \\
\text { judgment of the clinical trial director } \\
\text { because they may affect the clinical trial } \\
\text { results. } \\
\text { Participants who have no experience in } \\
\text { using a dental unit chair system. }\end{array}$ \\
\hline
\end{tabular}




\subsection{Statistical Analysis}

All of the statistical data analyses were performed using statistical software (SPSS release 25.0, IBM, Chicago, IL, USA) ( $\alpha=0.05)$. First, the normal distribution of the data was investigated through the Shapiro-Wilk test, and the normal distribution was checked. A correlation analysis was conducted by assessing Pearson's correlation coefficient (PCC) in order to analyze the impact of each factor on the overall satisfaction with the dental unit chair. The correlations were divided into perfect correlation ( $\mathrm{PCC}=-1$ or 1 ), strong correlation ( $\mathrm{PCC}=-0.7$ to -0.9 or 0.7 to 0.9 ), ordinary correlation ( $\mathrm{PCC}=-0.4$ to -0.6 or 0.4 to 0.6 ), and weak correlation ( $\mathrm{PCC}=-0.1$ to -0.3 or 0.1 to 0.3 ) [35].

\section{Results}

3.1. Results of the Correlations of the Overall Satisfaction Score of the Dental Unit Chair with the Questionnaire Items

The overall satisfaction score of the dental unit chair was significantly correlated with 38 questionnaire items $(p<0.05$; Table 4$)$, except for the headrest reclining angle of the patient seat $(p=0.07)$, the ergonomic design of the dentist chair $(p=0.076)$, and the overall satisfaction with the dentist chair $(p=0.064)$. Furthermore, the overall satisfaction score of the dental unit chair was strongly correlated with elements such as the quality of the design and appearance of the dental unit chair $(P C C=0.781)$, maintenance $(P C C=0.784)$, and the overall satisfaction with the water fountain and cuspidor ( $\mathrm{PCC}=0.703$ ) (Table 4). All of the other items were ordinarily correlated with the overall satisfaction score of the dental unit chair score (Table 4).

Table 4. Results of the correlation analysis between the overall satisfaction score of the chair unit and the questionnaire items.

\begin{tabular}{|c|c|c|c|c|}
\hline \multirow[b]{2}{*}{ Number } & & \multirow[b]{2}{*}{ Items } & \multicolumn{2}{|c|}{ Overall Satisfaction Score } \\
\hline & & & $\begin{array}{l}\text { Correlation } \\
\text { Coefficient }\end{array}$ & $p$ \\
\hline 1 & \multirow{4}{*}{ Overall evaluation } & Price & 0.648 & $<0.001$ * \\
\hline 2 & & Versatility of function & 0.64 & $<0.001 *$ \\
\hline 3 & & Design and appearance quality & 0.781 & $<0.001$ * \\
\hline 4 & & Maintenance & 0.784 & $<0.001 *$ \\
\hline 5 & \multirow{4}{*}{ Light } & Convenience of light head movement & 0.568 & $0.002 *$ \\
\hline 6 & & Convenience of color temperature control & 0.426 & $0.03 *$ \\
\hline 7 & & Influence of illuminance & 0.634 & $0.001 *$ \\
\hline 8 & & Overall satisfaction of light & 0.629 & $0.001 *$ \\
\hline 9 & \multirow{7}{*}{ Patient seat } & Appropriate length and area for each part & 0.403 & $0.041 *$ \\
\hline 10 & & Back reclining angle & 0.498 & $0.01 *$ \\
\hline 11 & & Head rest recline angle & 0.361 & 0.07 \\
\hline 12 & & Backrest reclining speed & 0.401 & $0.042 *$ \\
\hline 13 & & Backrest seat thickness & 0.405 & $0.04 *$ \\
\hline 14 & & Convenience of auxiliary handle & 0.504 & 0.009 * \\
\hline 15 & & Overall satisfaction of patient seat & 0.587 & $0.002 *$ \\
\hline 16 & \multirow{3}{*}{ Foot controller } & Ease of operation & 0.679 & $<0.001 *$ \\
\hline 17 & & Pedal pressure during operation & 0.645 & $<0.001 *$ \\
\hline 18 & & Overall satisfaction of foot controller & 0.581 & $0.002 *$ \\
\hline
\end{tabular}


Table 4. Cont.

\begin{tabular}{|c|c|c|c|c|}
\hline \multirow[b]{2}{*}{ Number } & & \multirow[b]{2}{*}{ Items } & \multicolumn{2}{|c|}{ Overall Satisfaction Score } \\
\hline & & & $\begin{array}{l}\text { Correlation } \\
\text { Coefficient }\end{array}$ & $p$ \\
\hline 19 & \multirow{7}{*}{$\begin{array}{l}\text { Water fountain and } \\
\text { cuspidor }\end{array}$} & Ease of operation & 0.633 & $0.001 *$ \\
\hline 20 & & The height and area of the cuspidor & 0.562 & $0.003 *$ \\
\hline 21 & & Cup position & 0.609 & $<0.001 *$ \\
\hline 22 & & $\begin{array}{l}\text { Water purification and wastewater treatment } \\
\text { facilities }\end{array}$ & 0.608 & $0.001 *$ \\
\hline 23 & & Water quantity and speed & 0.67 & $<0.001 *$ \\
\hline 24 & & Convenience of cleaning the cuspidor & 0.598 & $0.001 *$ \\
\hline 25 & & $\begin{array}{l}\text { Overall satisfaction of water fountain and } \\
\text { cuspidor }\end{array}$ & 0.703 & $<0.001$ * \\
\hline 26 & \multirow{6}{*}{ Monitor } & Screen size & 0.508 & $0.008 *$ \\
\hline 27 & & $\begin{array}{l}\text { Distance between monitor and } \\
\text { operator/patient }\end{array}$ & 0.492 & $0.011 *$ \\
\hline 28 & & Convenience to move & 0.449 & $0.021 *$ \\
\hline 29 & & Resolution & 0.563 & $0.003 *$ \\
\hline 30 & & Arm support & 0.555 & $0.003 *$ \\
\hline 31 & & Overall satisfaction of monitor & 0.545 & $0.004^{*}$ \\
\hline 32 & \multirow{6}{*}{$\begin{array}{l}\text { Bracket table and } \\
\text { controller }\end{array}$} & Size & 0.576 & $0.002 *$ \\
\hline 33 & & Weight & 0.587 & $0.002 *$ \\
\hline 34 & & Mounting stability & 0.627 & 0.001 * \\
\hline 35 & & Controller user interface & 0.442 & $0.024 *$ \\
\hline 36 & & Stability of table arm operation & 0.579 & $0.002 *$ \\
\hline 37 & & $\begin{array}{l}\text { Overall satisfaction of bracket table and } \\
\text { controller }\end{array}$ & 0.564 & $0.003 *$ \\
\hline 38 & \multirow{4}{*}{ Dentist chair } & Backrest angle and shape & 0.45 & $0.021 *$ \\
\hline 39 & & Convenience to move & 0.517 & $0.007 *$ \\
\hline 40 & & Human engineering design & 0.354 & 0.076 \\
\hline 41 & & Overall satisfaction of dentist chair & 0.369 & 0.064 \\
\hline
\end{tabular}

* Significance determined using Pearson's correlation analysis, $p<0.05$.

3.2. Results of the Correlations of the Overall Satisfaction Score of Each Component (Light, Patient Seat, Foot Controller, Water Fountain and Cuspidor, Monitor, Bracket Table and Controller, and Dentist Chair) of the Dental Unit Chair with the Questionnaire Items

The overall satisfaction with each component of the dental unit chair was significantly correlated with the questionnaire items, except for the convenience of the movement of the light head $(p=0.064)(p<0.05$; Table 5$)$.

The overall satisfaction with the light of the dental unit chair was strongly correlated with the convenience of the color temperature control $(\mathrm{PCC}=0.866)$ and the influence of the illumination (PCC =0.803), and highly correlated with the convenience of the color temperature control (Table 5).

The overall satisfaction with the patient seat of the dental unit chair was strongly correlated with the appropriate length and area for each part $(\mathrm{PCC}=0.821)$, back reclining angle $(P C C=0.727)$, backrest reclining speed $(\mathrm{PCC}=0.700)$, and convenience of the auxiliary handle $(\mathrm{PCC}=0.700)$, and highly correlated with appropriate length and area for each part (Table 5). 
Table 5. Results of the correlation analysis between the overall satisfaction of each element constituting the chair unit and the questionnaire items.

\begin{tabular}{|c|c|c|c|c|}
\hline \multirow[b]{2}{*}{ Number } & & \multirow[b]{2}{*}{ Items } & \multicolumn{2}{|c|}{ Overall Satisfaction Score } \\
\hline & & & $\begin{array}{l}\text { Correlation } \\
\text { Coefficient }\end{array}$ & $p$ \\
\hline 1 & \multirow{3}{*}{ Light } & Convenience of light head movement & 0.369 & 0.064 \\
\hline 2 & & Convenience of color temperature control & 0.866 & $<0.001$ * \\
\hline 3 & & Influence of illuminance & 0.803 & $<0.001$ * \\
\hline 4 & \multirow{6}{*}{ Patient seat } & Appropriate length and area for each part & 0.821 & $<0.001 *$ \\
\hline 5 & & Back reclining angle & 0.727 & $<0.001 *$ \\
\hline 6 & & Headrest recline angle & 0.436 & $0.026^{*}$ \\
\hline 7 & & Back rest reclining speed & 0.700 & $<0.001 *$ \\
\hline 8 & & Back rest seat thickness & 0.643 & $<0.001$ * \\
\hline 9 & & Convenience of auxiliary handle & 0.700 & $<0.001 *$ \\
\hline 10 & \multirow{2}{*}{ Foot controller } & Ease of operation & 0.736 & $<0.001 *$ \\
\hline 11 & & Pedal pressure during operation & 0.737 & $<0.001 *$ \\
\hline 12 & \multirow{6}{*}{$\begin{array}{l}\text { Water fountain and } \\
\text { cuspidor }\end{array}$} & Ease of operation & 0.748 & $<0.001 *$ \\
\hline 13 & & The height and area of the cuspidor & 0.824 & $<0.001 *$ \\
\hline 14 & & Cup position & 0.862 & $<0.001 *$ \\
\hline 15 & & $\begin{array}{l}\text { Water purification and wastewater treatment } \\
\text { facilities }\end{array}$ & 0.722 & $<0.001$ * \\
\hline 16 & & Water quantity and speed & 0.686 & $<0.001 *$ \\
\hline 17 & & Convenience of cleaning the cuspidor & 0.774 & $<0.001$ * \\
\hline 18 & \multirow{5}{*}{ Monitor } & Screen size & 0.871 & $<0.001 *$ \\
\hline 19 & & $\begin{array}{l}\text { Distance between monitor and } \\
\text { operator/patient }\end{array}$ & 0.923 & $<0.001 *$ \\
\hline 20 & & Convenience to move & 0.877 & $<0.001 *$ \\
\hline 21 & & Resolution & 0.811 & $<0.001$ * \\
\hline 22 & & Arm support & 0.865 & $<0.001 *$ \\
\hline 23 & \multirow{5}{*}{$\begin{array}{l}\text { Bracket table and } \\
\text { controller }\end{array}$} & Size & 0.824 & $<0.001$ * \\
\hline 24 & & Weight & 0.948 & $<0.001 *$ \\
\hline 25 & & Mounting stability & 0.899 & $<0.001 *$ \\
\hline 26 & & Controller user interface & 0.836 & $<0.001 *$ \\
\hline 27 & & Stability of table arm operation & 0.899 & $<0.001 *$ \\
\hline 28 & \multirow{3}{*}{ Dentist chair } & Back rest angle and shape & 0.768 & $<0.001 *$ \\
\hline 29 & & Convenience to move & 0.780 & $<0.001$ * \\
\hline 30 & & Human engineering design & 0.932 & $<0.001 *$ \\
\hline
\end{tabular}

* Significance determined using Pearson's correlation analysis, $p<0.05$.

The overall satisfaction with the foot controller of the dental unit chair was strongly correlated with ease of operation $(\mathrm{PCC}=0.736)$ and pedal pressure during operation $(\mathrm{PCC}=0.737)$, and highly correlated with the two elements (Table 5).

The overall satisfaction with the water fountain and cuspidor of the dental unit chair was strongly correlated with the ease of operation (PCC $=0.748)$, height and area of the cuspidor $(\mathrm{PCC}=0.824)$, cup position $(\mathrm{PCC}=0.862)$, water purification and wastewater 
treatment facilities (PCC $=0.722)$, and convenience of cleaning the cuspidor $(\mathrm{PCC}=0.774)$, and highly correlated with the height and area of the cuspidor (Table 5).

The overall satisfaction with the monitor of the dental unit chair was strongly correlated with the monitor size $(\mathrm{PCC}=0.871)$, the distance between the monitor and the operator/patient $(\mathrm{PCC}=0.923)$, its convenience to move $(\mathrm{PCC}=0.877)$, its resolution $(\mathrm{PCC}=0.811)$, and its arm support $(\mathrm{PCC}=0.865)$, and highly correlated with the distance between the monitor and the operator/patient (Table 5).

The overall satisfaction with the bracket table and controller of the dental unit chair was strongly correlated with the bracket table and controller size $(\mathrm{PCC}=0.824)$, weight (PCC $=0.948)$, mounting stability $(\mathrm{PCC}=0.899)$, controller UI $(\mathrm{PCC}=0.836)$, and stability of the table arm operation (PCC $=0.899)$, and highly correlated with its weight (Table 5).

The overall satisfaction with the dentist chair of the dental unit chair was strongly correlated with the backrest angle and shape (PCC $=0.768)$, convenience to move (PCC $=0.780)$, and human engineering design $(\mathrm{PCC}=0.932)$, and highly correlated with the human engineering design (Table 5).

\section{Discussion}

This in vivo study conducted a survey of the user satisfaction with a dental unit chair in order to highlight the factors affecting Korean dentists' satisfaction. The null hypothesis was that the questionnaire items in this study would not affect the satisfaction with the dental unit chair; however, the null hypothesis was dismissed $(p<0.05$; Tables $2-4)$. In this study, a reliability test of the questionnaire items was conducted. This study proved that most of the derived factors might affect the overall satisfaction with the dental unit chair.

To the best of our knowledge, in several previous studies on the dental unit chair, there were no studies providing quantitative information regarding the factors to consider while purchasing a dental unit chair. Thus, an appropriate comparison with previous studies is difficult. However, quantitative information on factors to consider when purchasing a dental unit chair can help the dentist in their decision, as it can confirm what items to consider when choosing a dental unit chair. In addition, this information will be important information for dental unit chair manufacturers, as they can check the design preferred by dentists and the factors that are important to them when developing or improving the chair unit. Furthermore, this study may become a new guideline for the evaluation of the chair unit because it was able to derive important factors by evaluating the dental unit chair.

Previous studies have reported on the musculoskeletal risk factors when dentists use a dental unit chair [29-31]. Electromyographic evaluation was performed in order to assess the musculoskeletal risks, and it was reported that elements of the dental unit chair design had an effect on the dentist's musculoskeletal health [27,29,30]. Furthermore, elements of the dental unit chair design may have a significant impact on the aesthetic elements of its appearance. However, they should not affect the dentist's musculoskeletal health while using the unit for a long time. The design elements of a dental unit chair may possess some risk factors, such as percutaneous injuries [23], the risk of cross infection [17], work convenience [1-3], and musculoskeletal diseases. Thus, this study highlighted the design elements that affect the dental unit chair, with two investigators (K.S. and K.-B.L.) subdividing each component of the dental unit chair. Additionally, in this study, a reliability test of the derived elements was performed, and the appropriate reliability for a survey of satisfaction with the dental unit chair was tested.

This study reported that the design and appearance quality, maintenance, and overall satisfaction with the water fountain and cuspidor may have the greatest impact on the overall satisfaction with the dental unit chair (Table 2). From the perspective of dentists, for the overall satisfaction with the dental unit chair, the design and appearance quality of the dental unit chair-which can be checked by the naked eye-would be the most important factors. Additionally, in the interviews after the survey in this study, it was found that the respondents preferred the dental unit chair that could be used stably without any failure for a long time, as they had to receive patients continuously, and placed priority on 
convenient maintenance after a failure. From the perspective of dentists, the water fountain and cuspidor are the places where there is a risk of cross contamination, as they are used by patients and dental hygienists [5,17]. Additionally, in the interviews, it was noted that the water fountain and cuspidor took up great proportions of the external size of the dental unit chair. Thus, the overall satisfaction with the dental unit chair strongly interacted with each of the three factors, and it was highlighted as an important factor.

In previous studies, it has been reported that the dentist's posture affected the muscle activities in the neck and shoulders in the treatment process [26,27,30], and various components of the dental unit chair may affect the dentist's posture [6]. This study highlighted the factors that have strong correlations with the overall satisfaction score with each component of the dental unit chair (Table 5). The study results showed that the satisfaction with various components of the dental unit chair differed depending on their design and functional importance (Table 5).

There are some potential limitations of this study. The study included a small number of subjects. Results from more subjects are needed. Thus, it is necessary to conduct an additional study with more subjects, referring to the research methods and results of this in vivo study. In addition, while evaluating the design of the dental unit chair system, the induction of musculoskeletal disorders is an important point to consider. Therefore, the dentist's knowledge of ergonomic laws is important, and additional studies of musculoskeletal disorders should be performed. In addition, because this study was only from the perspective of dentists, additional studies are needed from the perspective of dental hygienists and patients in the future.

\section{Conclusions}

Within the limitations of this in vivo study, a survey of user satisfaction with the dental unit chair was conducted with the dentists of South Korea, and the factors affecting the satisfaction are as follows:

1. Because the design and appearance quality, maintenance, and overall satisfaction with the water fountain and cuspidor may have the greatest impact on the overall satisfaction with the dental unit chair, the improvement of these factors may bring about the enhancement of the overall satisfaction.

2. Additionally, regarding the dental unit chair components, the following factors have the greatest impact on the overall satisfaction with the dental unit chair: with regard to light, the convenience of color temperature control; with regard to the patient seat, the appropriate length and area for each part; with regard to the foot controller, the ease of operation and pedal pressure during operation; with regard to the water fountain and cuspidor of the dental unit chair, the height and area of the cuspidor and cup position; with regard to the monitor of the dental unit chair, the distance between monitor and operator/patient; with regard to the bracket table and controller of the dental unit chair, the weight; and with regard to the dentist chair, human engineering design. The improvement of these factors may bring about the enhancement of the satisfaction with each component of the dental unit chair.

Author Contributions: Conceptualization, methodology, investigation, formal analysis, writingoriginal draft, and visualization, K.S.; writing — original draft, and writing — review and editing, Y.-T.S.; data curation, writing—original draft, and writing—review and editing, M.-U.J.; validation, data curation, supervision, and project administration, K.-B.L. All authors have read and agreed to the published version of the manuscript.

Funding: This research was financially supported by the Ministry of Trade, Industry and Energy (MOTIE) and Korea Institute for the Advancement of Technology (KIAT) through the National Innovation Cluster R\&D program (P0016241_User-friendly chair unit development for digital information provision). 
Institutional Review Board Statement: The study was conducted according to the guidelines of the Declaration of Helsinki and approved by the Institutional Review Board of Kyungpook National University Dental Hospital (protocol code: KNUDH-2021-04-04-01; approval date: 28 May 2021).

Informed Consent Statement: Not applicable.

Data Availability Statement: The data are included within the article.

Acknowledgments: The authors thank the researchers of the Advanced Dental Device Development Institute, Kyungpook National University, for their time and contributions to the study.

Conflicts of Interest: The authors declare no conflict of interest. The funders had no role in the study's design; the data collection, analyses, or interpretation; the manuscript writing; or the decision to publish the results.

\section{References}

1. Tamazawa, Y.; Watanabe, M.; Kikuchi, M.; Takatsu, M.; Tamazawa, K.; Yumoto, N.; Hyvarinen, P. A new dental unit for both patients in wheelchairs and general patients. Gerodontology 2004, 21, 53-59. [CrossRef] [PubMed]

2. Foutse, M.; Youssoufa, M.; Kapen, P.T.; Tchounang, S.C. Low-cost mobile dental unit for oral care service delivery in third world countries: From concept to operation. Health Technol. 2020, 10, 1525-1532. [CrossRef]

3. Fikriah, I.; Asfirizal, V.; Purnamasari, C.B.; Ikbal, M. Design simulator dental unit for practice of dental medicine students. Eur. J. Mol. Clin. Med. 2020, 7, 694-700.

4. Lakshmi, K.; Madankumar, P.D. Development of modified dental chair to accomodate both wheelchair bound patients and general population. Disabil. Rehabil. Assist. Technol. 2020, 15, 467-470. [CrossRef] [PubMed]

5. Shukla, S.; Singh, S.; Batra, M.; Gijwani, D.; Leimaton, T.; Mangal, P. Bacterial contamination of dental unit waterlines: Knowledge and attitude among dental practitioners. J. Curr. Med. Res. Pract. 2020, 5, 355. [CrossRef]

6. Haddad, O.; Sanjari, M.A.; Amirfazli, A.; Narimani, R.; Parnianpour, M. Trapezius muscle activity in using ordinary and ergonomically designed dentistry chairs. Int. J. Occup. Environ. Med. 2012, 3, 76-83. [PubMed]

7. Choi, J.O.; Lee, Y.H.; Nam, S.H. Factors affecting surface management of dental unit chair. Biomed. Res. 2018, $29,15$.

8. $\quad$ Soares, C.J.; Bragança, G.F.D.; Pereira, R.A.D.S.; Rodrigues, M.D.P.; Braga, S.S.L.; Oliveira, L.R.S.; Price, R.B. Irradiance and radiant exposures delivered by LED light-curing units used by a left and right-handed operator. Braz. Dent. J. 2018, 29, 282-289. [CrossRef]

9. Tiwari, A.; Shyagali, T.; Kohli, S.; Joshi, R.; Gupta, A.; Tiwari, R. Effect of dental chair light on enamel bonding of orthodontic brackets using light cure based adhesive system: An in-vitro study. Acta Inform. Med. 2016, 24, 317. [CrossRef]

10. Lee, J.E.; Lee, B.D.; Wright, G.Z.; Kupietzky, A. The dental office. Wright Behav. Manag. Dent. Child. $2021,18,275-287$.

11. Levy, H.; Rotenberg, L.R. Tools and equipment for managing special care patients anywhere. Dent. Clin. 2016, 60, 567-591. [CrossRef]

12. Saddle, B. Dental chairs delivery systems. Br. Dent. J. 2003, 194, 175.

13. Abdolalizadeh, M.; Jahanimoghadam, F. Musculoskeletal disorders in dental practitioners and ergonomic strategies. Anat. Sci. Educ. 2015, 12, 161-166.

14. Weekend, H.O. New products and focus on dental chairs and delivery systems. Br. Dent. J. 2008, 204, 155.

15. Das, H.; Motghare, V.; Singh, M. Ergonomics in dentistry: Narrative review. Int. J. Appl. Dent. Sci. 2018, 4, 104-110.

16. Dahlen, G. Biofilms in Dental Unit Water Lines. Oral Biofilms 2021, 29, 12-18.

17. O'Donnell, M.J.; Shore, A.C.; Coleman, D.C. A novel automated waterline cleaning system that facilitates effective and consistent control of microbial biofilm contamination of dental unit chair waterlines: A one-year study. J. Dent. 2006, 34, 648-661. [CrossRef] [PubMed]

18. Volgenant, C.M.C.; Persoon, I.F. Microbial water quality management of dental unit water lines at a dental school. J. Hosp. Infect. 2019, 103, e115-e117. [CrossRef] [PubMed]

19. Lal, B.; Ravindra, K.; Biswal, M. Appraisal of microbial contamination of dental unit water systems and practices of general dental practitioners for risk reduction. Environ. Sci. Pollut. Res. 2018, 25, 33566-33572. [CrossRef] [PubMed]

20. Baudet, A.; Lizon, J.; Martrette, J.M.; Camelot, F.; Florentin, A.; Clément, C. Dental unit waterlines: A survey of practices in Eastern France. Int. J. Environ. Res. Public Health 2019, 16, 4242. [CrossRef]

21. Rosa, G.M.; Elizondo, M.L. Use of a gesture user interface as a touchless image navigation system in dental surgery: Case series report. Imaging Sci. Dent. 2014, 44, 155-160. [CrossRef] [PubMed]

22. Song, E.S.; Kim, W.H.; Lee, B.H.; Han, D.W.; Lee, J.H.; Kim, B. Assessment of Color Perception and Preference with Eye-Tracking Analysis in a Dental Treatment Environment. Int. J. Environ. Res. Public Health 2021, 18, 7981. [CrossRef] [PubMed]

23. Shamim, T. Occupational nonspecific granulomatous osteomyelitis of third metacarpal bone as a sequel to percutaneous injury on left hand due to sharp dental bur: A self reported case. J. Coll. Physicians Surg. Pak. 2015, 25, 629-631. [PubMed]

24. Dong, H.; Loomer, P.; Barr, A.; LaRoche, C.; Young, E.; Rempel, D. The effect of tool handle shape on hand muscle load and pinch force in a simulated dental scaling task. Appl. Ergon. 2007, 38, 525-531. [CrossRef] 
25. Blanc, D.; Farre, P.; Hamel, O. Variability of musculoskeletal strain on dentists: An electromyographic and goniometric study. Int. J. Occup. Saf. Ergon. 2014, 20, 295-307. [CrossRef]

26. Rafeemanesh, E.; Jafari, Z.; Kashani, F.O.; Rahimpour, F. A study on job postures and musculoskeletal illnesses in dentists. Int. J. Occup. Med. Environ. Health 2013, 26, 615-620. [CrossRef]

27. Petrović, V.; Pejčić, N.; Bulat, P.; Đurić-Jovičić, M.; Miljković, N.; Marković, D. Evaluation of ergonomic risks during dental work. Balk. J. Dent. Med. 2016, 20, 33-39. [CrossRef]

28. Franz, M.; Zenk, R.; Vink, P.; Hallbeck, S. The effect of a lightweight massage system in a car seat on comfort and electromyogram J. Manip. Physiol. Ther. 2011, 34, 107-113. [CrossRef]

29. Gandavadi, A.; Ramsay, J.R.E.; Burke, F.J.T. Assessment of dental student posture in two seating conditions using RULA methodology-A pilot study. Br. Dent. J. 2007, 203, 601-605. [CrossRef]

30. García-Vidal, J.A.; López-Nicolás, M.; Sánchez-Sobrado, A.C.; Escolar-Reina, M.P.; Medina-Mirapeix, F.; Bernabeu-Mora, R. The combination of different ergonomic supports during dental procedures reduces the muscle activity of the neck and shoulder. $J$. Clin. Med. 2019, 8, 1230. [CrossRef]

31. Pejčić, N.; Petrović, V.; Đurić-Jovičić, M.; Medojević, N.; Nikodijević-Latinović, A. Analysis and prevention of ergonomic risk factors among dental students. Eur. J. Dent. Educ. 2021, 25, 460-479. [CrossRef] [PubMed]

32. Vos, L.M.; Habibović, M.; Nyklíček, I.; Smeets, T.; Mertens, G. Optimism, mindfulness, and resilience as potential protective factors for the mental health consequences of fear of the coronavirus. Psychiatry Res. 2021, 300, 113927. [CrossRef] [PubMed]

33. Tzelves, L.; Glykas, I.; Fragkoulis, C.; Mitsikostas, D.D.; Skolarikos, A.; Welk, B.; Dellis, A. Validity and reliability of the Greek version of the neurogenic bladder symptom score (NBSS) questionnaire in a sample of Greek patients with multiple sclerosis. World J. Urol. 2021, 39, 2697-2702. [CrossRef] [PubMed]

34. Opitz, M.C.; Newman, E.; Mellado, A.S.A.V.; Robertson, M.; Sharpe, H. The psychometric properties of orthorexia nervosa assessment scales: A systematic review and reliability generalization. Appetite 2020, 155, 104797. [CrossRef] [PubMed]

35. Son, K.; Lee, K.B. Effect of computer literacy on the working time of the dental CAD software program. J. Prosthodont. Res. 2021, 65, 255-260. [CrossRef] [PubMed]

36. Shrestha, N. Factor analysis as a tool for survey analysis. Am. J. Appl. Math. Stat. 2021, 9, 4-11. [CrossRef] 